\title{
Measuring Students Satisfaction in Using Learning Management System
}

\author{
https://doi.org/10.3991/ijet.v14.i04.9427 \\ Jenny Ohliati ${ }^{(凶)}$, Bahtiar S. Abbas \\ Bina Nusantara University, Jakarta, Indonesia \\ jenny.ohliati@binus.ac.id
}

\begin{abstract}
The purpose of this study to determine what are the influenced factors for student satisfaction on learning management system at a private university that operates online learning system. The research was conducted to find out whether there is influence of information quality, system quality, service quality, perceived usefulness, perceived ease of use, and communication quality to student satisfaction toward learning management system. This study took a sample of 100 student respondents at the university. The used analytical method to test the effect is partial least square. The results show that information quality, service quality, and perceived ease of use have a significant effect on student satisfaction. Service quality is the most dominant factor that affects the satisfaction of students to learning management system.
\end{abstract}

Keywords - Learning management system, online learning, partial least square

\section{Introduction}

The growth of internet has an impact on the development of education, where education is now required to be flexible [1]. Flexible in learning methods that can be done anywhere and anytime without any geographical restrictions has becomes a highly demand to fulfill the educational needs of professionals, entrepreneurs and even housewives who want to continue their education to a higher level.

Media technology that connect the learning process of classroom e-learning is learning management system (LMS) [2]. LMS is an application that manages online learning systems, distributes learning materials, and enables interaction between lectures and students [3] LMS supports teaching and learning activities, helps to organize e-learning content on storage systems, provides unlimited access to e-learning materials so that the tracking students' progress becomes easier.

LMS is not a new thing nowadays, universities that run e-learning mostly adopt this system. There is one private university that runs e-learning in Jakarta, Indonesia. This private university is an information technology based educational institution that has experience in conducting education using Information and Communications Technology (ICT) for the students. One of ICT-based learning system is the online 
learning system where teaching and learning process is done through web-based learning.

Students will be satisfied with the process of learning by using the media on the website because the interaction via website is fun, encouraging the learning process and success compared with conventional lectures [4]. Based on the prior reserachers, there are several factors that influence student's satisfaction toward LMS. According to Ramayah and Lee (2012) that the satisfaction of students toward LMS is influenced by the quality of the information, system and services provided by educational institutions. The quality of communication in the LMS needs to be concerned, as the learning process runs via online without meeting each other. The quality of good communication through media affects student satisfaction [5]. Another factor of satisfaction, according to Islam (2015) is where the LMS is easy to learn and can help the learning performance.

The purpose of this study to determine what factors that affect student satisfaction on learning management system at a private university that organizes online learning system.

\section{$2 \quad$ Literature Review}

\subsection{Information quality}

According to Miller (1996), the quality of information is an information where the users are able to use it and get helped. The quality of information can be identified by two stages which are highlighting the important attribute information and determining how that attribute affects the user. The examined attributes by Miller are relevance, accuracy, timeless, completeness, coherence, format, accessibility, compatibility, security, and validity.

DeLone and McLean (2003) examine the relationship between the quality of information and individual impacts that can be measured by accuracy, timeliness, completeness, relevancy, and consistency. According to Ramirez, Rondan, Arenas, \& Alfaro (2017), the quality of information can be defined as the output characteristics offered by information systems, such as: accuracy, timeliness, and completeness of metrics. Similarly, conducted research by Alsabawy (2016), quality of information is measured by using elements of importance, availability, usability, understanbility, and conciseness.

\subsection{System quality}

Asda According to Almarashdeh, Sahari, Zin, \& Alsmadi (2010), system quality is defined as the stability, reliability and suitability of hardware and software that provides the required information. Quality systems in LMS measures the intrinsic features of technology including system performance and user interface. The used elements to measure LMS are responsetime, usability, availability, reliability, completeness, system flexibility, and security. Meanwhile, according to Urbach, Smolnik, \& 
Riempp (2010), to measure the quality of employee portal system consider the characteristics of performance, functionality, and usability.

System quality is also defined as the compatibility, reliability of the system, and the stability of software and hardware where information needs to be supported [6].

\subsection{Service quality}

According to Almarashdeh, Sahari, Zin, \& Alsmadi (2010), service quality is concerned with overall support provided by distance learning service providers or technology. Service quality can be measured through access to technical support, prompt responsiveness, assurance, empathy, and subsequent services.

In the study of Alsabawy (2016) to measure the services quality using efficiency, availability, fulfillment, privacy, responsiveness, and contact. Similarly, research conducted by Gorla, Somers, \& Wong (2010) to determine the organizational influence of system quality, information quality, and service quality. Service quality is measured by responsiveness, reliability, empathy, and assurance elements

\subsection{Perceived usefulness}

Davis (2003) explains that perceived usefulness is the level of confidence a person to a system that can improve its performance. Alsabawy (2016) adopted the notion of Davis and measured perceived usefulness using elements of accomplish quickly, improving performance, increasing productivity, easier study, overall usefulness.

\subsection{Perceived ease of use}

According to Davis (2003) perceived ease of use is the level of confidence a person against a system that can free his business from the use of the system. To measure perceived ease of use, Davis uses elements such as ease of use, user expectation, user interaction, flexibility, increase performance, and easy to use.

\subsection{Communication quality}

Communication is an interpersonal process for sending and receiving information so that messages are well delivered. Information technology has played an important role in providing communication support for an organization. Some of the factors that determine IT technology can be used to provide communication support such as participants, resources and goals, media, place, and time [7].

In the research of Wang \& Chiu (2011) which measures communication quality using elements of information quality, system quality, and service quality shows the empirical results which the quality of information and the quality of the system affect the communication quality significantly, where the quality of the system can improve the quality of communication between users in using e-learning system. 


\subsection{User satisfaction}

User satisfaction is defined by Almarashdeh (2016) as a general evaluation of the user experience of the system and likely to influence users. Research conducted by Amin, Rezaei, \& Abolghasemi (2014) shows user satisfaction with mobile websites positively influenced by trust, perceived usefulness and perceived ease of use.

Wang \& Chiu (2011) explained in the results of his research that the relationship between the communication quality has a significant relationship to user satisfaction. Communication quality helps users share information, provide feedback, negotiate and integrate system users. It can also improve user satisfaction with e-learning system learning.

\section{$2.8 \quad$ Research model}

Information quality is information that can be felt and used by users [8]. Information quality can be identified by two stages of highlighting which information attributes are important and determining how those attributes affect the user. In this study, information quality construction refers to the theory developed by DeLone and McLean (1992) and Wang \& Wang (2009) where using accuracy, relevacy, completeness, availability, usability, and understandability indicators in measuring information quality.

Almarashdeh, Sahari, Zin, \& Alsmadi (2010) defines system quality as the stability, reliability, and compatibility of hardware and software that provides the required information. System quality in LMS measures intrinsic technology features including system performance and user interface. The system quality construct in this study refers to the theory developed by DeLone and McLean (1992), Alsabawy, Cater-Steel, \& Soar (2016), and Urbach, Smolnik, \& Riempp (2010) which use indicators of reliability, functionality, navigation, flexibility, accessibility, and facility in measuring system quality.

According to Almarashdeh, Sahari, Zin, \& Alsmadi (2010), service quality is concerned with overall support provided by distance learning service providers or technology. Service quality can be measured through access to technical support, rapid responsiveness, assurance, empathy, and subsequent services. Service quality construct refers to the theory developed by DeLone McLean (2003) and Urbach, Smolnik, \& Riempp (2010) where using indicators of availability, reliability, responsive, and assurance in measuring service quality.

Davis (1989) describes perceived usefulness is the level of confidence a person to a system can improve its performance. Similarly, research conducted by Arbaugh (2000a, 2000b) argues that perceived usefulness of electronic media in the delivery of learning can improve students' attitudes toward experience and in the future they will adopt learning via internet. The results support the argument and confirm that perceived usefulness positively affects student satisfaction. Perceived usefulness constructs in this study refers to the theory of Davis (1989) and Alsabaway (2016) using improving performance indicators, increasing productivity, easier study, and overall usefulness in measuring perceived usefulness. 
Perceived ease of use is the level of confidence in a system that can free its business from the use of the system (Davis, 2003). The perceived ease of use construct in this study refers to Davis (1989) and Amin, Rezaei, \& Abolghasemi (2014) theory using easy to use, user interaction, user expectation, and flexibility in measuring perceived ease of use.

Communication quality depends on whether both parties are motivated to continue to interact. This interaction through words and language. Through language, learners can seek information and send information about their opinions [9]. Aspects of communication quality to assess whether learners get the benefit from interactive communication, such as sharing, feedback and negotiation in discussions [5]. Construct communication quality in this research refers to the theory developed by Wang and Chiu (2011) which consists of chat forum, video conference, user's feedback, interchange opinions, review opinions, integrate opinions.

Referring to DeLone and McLean (2003), user satisfaction describes the user's response to the use of the information system. The user satisfaction construct in this study refers to the theory developed by Alsabawy (2013). User satisfaction uses experience, performance, and learning tool indicators.

Based on the explanation of the framework, it can be described the paradigm of realated research to information quality, system quality, service quality, perceived usefulness, perceived ease of use, and communication quality.

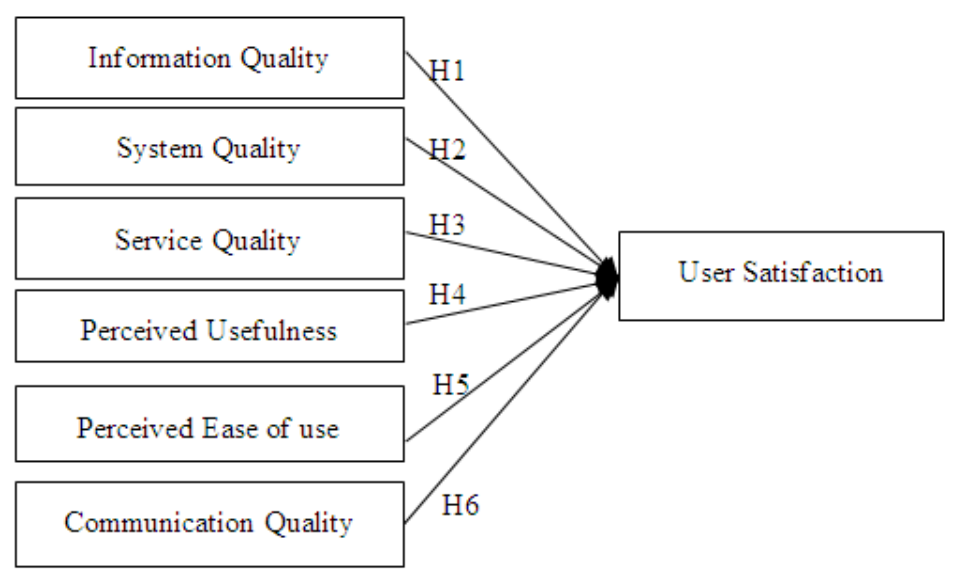

Fig. 1. Research Framework

Based on literature review and research framework, it can be formulated research hypothesis that is:

- H1: Information quality have a significant effect on user satisfaction.

- H2 : System quality have a significant effect on user satisfaction

- H3 : Service quality have a significant effect on user satisfaction

- H4 : Perceived usefulness have a significant effect on user satisfaction

- H5 : Perceived ease of use have a significant effect on user satisfaction 
- H6 : Communication quality have a significant effect on user satisfaction

\section{$3 \quad$ Research Method}

This study uses questionnaires as a means of data collection, as it is necessary to test the validity and reliability. The next stage is to analyze and interpret the obtained data in the field by using descriptive statistical analysis and inferential statistics. The number of samples taken is 100 students majoring in Master of Information Technology (MIT) and Master of Management Information Systems (MMIS). Spreading the questionnaire has been done by random sampling using google form, the samples obtained are 33 students majoring in MIT and 67 students majoring in MMIS. Measurement of questionnaires using Likert scale from 1 to 5 . The duration of survey is one month (in the period of November 2017). The inferential statistics method used in data analysis is Partial Least Square (PLS). Data obtained from the samples were analyzed using PLS based on SmartPLS 3.0 software.

\section{$4 \quad$ Result}

\subsection{Measurement model}

Measurement model is done to ensure that the measurement used is feasible to be measured by testing the validity and reliability. The performed analyzes or tests on the outer model are convergent validity, discriminant validity, composite reliability (CR), and average variance extracted (AVE).

The research model was built with 36 indicator items and consisted of 7 dimensions of student satisfaction characteristics. All indicators for the dimensions in each construct resulted in a loading factor $(\lambda)$ greater than 0.5 so no indicator was excluded from the following model:

Table 1. Result from Outer Model

\begin{tabular}{|c|c|c|c|c|}
\hline Construct & Dimension & $\lambda$ & CR & AVE \\
\hline \multirow{6}{*}{ Information quality } & Accuracy & 0.800 & \multirow{6}{*}{0,918} & \multirow{6}{*}{0,652} \\
\hline & Relevancy & 0.805 & & \\
\hline & Completeness & 0.800 & & \\
\hline & Availability & 0.790 & & \\
\hline & Usability & 0.852 & & \\
\hline & Understandability & 0.796 & & \\
\hline \multirow{6}{*}{ System quality } & Reliability & 0.805 & \multirow{6}{*}{0,901} & \multirow{6}{*}{0,504} \\
\hline & Functionality & 0.749 & & \\
\hline & Navigation & 0.650 & & \\
\hline & Flexibility & 0.715 & & \\
\hline & Accessibility & 0.743 & & \\
\hline & Facility & 0.655 & & \\
\hline \multirow{3}{*}{ Service quality } & Availability & 0.942 & \multirow{3}{*}{0,958} & \multirow{3}{*}{0,853} \\
\hline & Reliability & 0.954 & & \\
\hline & Responsive & 0.941 & & \\
\hline
\end{tabular}




\begin{tabular}{|c|c|c|c|c|}
\hline Construct & Dimension & $\lambda$ & CR & AVE \\
\hline & Assurance & 0.853 & & \\
\hline \multirow{4}{*}{ Perceived usefulness } & Improving Performance & 0.933 & \multirow{4}{*}{0,966} & \multirow{4}{*}{0,877} \\
\hline & Increasing Productivity & 0.933 & & \\
\hline & Easier Study & 0.932 & & \\
\hline & Overall Usefulness & 0.947 & & \\
\hline \multirow{4}{*}{ Perceived ease of use } & Easy to use & 0.852 & \multirow{4}{*}{0,966} & \multirow{4}{*}{0,757} \\
\hline & User interaction & 0.873 & & \\
\hline & User expectation & 0.871 & & \\
\hline & Flexibility & 0.883 & & \\
\hline \multirow{6}{*}{ Communication quality } & Forum chat & 0.778 & \multirow{6}{*}{0,930} & \multirow{6}{*}{0,691} \\
\hline & Video conference & 0.672 & & \\
\hline & User's feedback & 0.878 & & \\
\hline & Interchange opinions & 0.869 & & \\
\hline & Review opinions & 0.896 & & \\
\hline & Integrate opinions & 0.873 & & \\
\hline \multirow{3}{*}{ User satisfaction } & LMS experience & 0.935 & \multirow{3}{*}{0,965} & \multirow{3}{*}{0,903} \\
\hline & LMS performance & 0.966 & & \\
\hline & LMS learning tools & 0.950 & & \\
\hline
\end{tabular}

\subsection{Structural model}

The next step is the examination of the structural model which includes the ability of the independent variable to explain the dependent variable and the significance of the path relationship.

Table 2. Output $\mathrm{R}$ - Square

\begin{tabular}{|l|c|c|}
\hline & R-Square & R-Square Adjusted \\
\hline US & 0.847 & 0.837 \\
\hline
\end{tabular}

The result of R-Square is 0.847 means that the variability of user satisfaction can be well explained by variability of information quality (IQ), system quality (SQ), service quality (SEQ), perceived usefulness (PU), perceived ease of use (PEOU), and communication quality (CQ) of $84.7 \%$ and $15.3 \%$ is explained by variables outside of the research.

Table 3. User satisfaction evaluation model hypothesis

\begin{tabular}{|l|l|l|c|c|l|l|}
\hline No & Hypothesis & $(\boldsymbol{\beta})$ & T Statistics & P Values & \multicolumn{1}{|c|}{ Result } & \multicolumn{1}{|c|}{ Effect size } \\
\hline H1 & IQ -> US & 0.173 & 2.045 & 0.043 & Support & Medium \\
\hline H2 & SQ -> US & 0.146 & 1.501 & 0.136 & Not Support & Medium \\
\hline H3 & SEQ -> US & 0.218 & 3.690 & 0.000 & Support & Large \\
\hline H4 & PU -> US & 0.042 & 0.440 & 0.661 & Not Support & Small \\
\hline H5 & PEOU -> US & 0.431 & 4.195 & 0.000 & Support & Large \\
\hline H6 & CQ -> US & 0.031 & 0.570 & 0.570 & Not Support & Small \\
\hline
\end{tabular}

From the results of the study can be seen at table 3 that information quality proved significant because the value of p-value information quality is 0.043 , which is smaller than 0.05 . The value of Original Sample is 0.173 , meaning that if there is an increase of information quality of 1 unit will affect student's satisfaction of 0.173 units. 
This research result is similar with previous research conducted by Almarashdeh (2016) which states that information quality has the least influence of the factors studied because the information quality is based on the quality of the content and the accuracy of the content provided by the instructor and the LMS service. Similarly, what happens in the information quality at these colleges, where the information quality is based on the content information in accordance with the lectures taken such as lecture information, course material information, and information services available to students.

System quality proved not significantly affect user satisfaction because the value of p-value system quality is 0.136 , which is greater than 0.05 . This indicates that the system quality factor does not affect student's satisfaction with learning management system (LMS). From the results of questionnaires given by the students indicate that the interaction performance between pages needs to be improved, the LMS facility to connect with the library menu in the mobile phone app needs to be improved, and needs to be upgraded LMS for mobile phone application version. This research result is not similar with previous research conducted by Almarashdeh (2016) which states that high system quality is influenced by several factors such as one of the ease of accessibility of the use of LMS.

Service quality proved significantly affect user satisfaction because the value of $\mathrm{p}$ value service quality is 0.000 , which is smaller than 0.05 . The value of Original Sample is 0.218 , meaning that if there is an increase service quality of 1 unit will affect student satisfaction of 0.218 units. This research result is similar with previous research conducted by Almarashdeh (2016) which states that if the LMS provides reliable and available 24/7 service quality, and services ready for use by the instructor, then the instructor's satisfaction will increase. Similarly, what happens to service quality in this college, where service quality focus on services performed by staff admin to students.

Perceived usefulness proved to be insignificant in affecting user satisfaction because the value of p-value perceived usefulness is 0.661 , which is greater than 0.05 . This indicates that perceived usefulness factor does not affect student's satisfaction with learning management system (LMS). This research result is not similar with previous research conducted by Almarashdeh (2016) which states that the use of LMS that can be felt can make the instructor reuse it because LMS is an interesting factor in interacting with distance learners. However, the significance in this study can be concluded that the LMS system is the main platform of learning for students so that teaching and learning activities are done online.

Perceived ease of use proved to significantly affect user satisfaction. The Original Sample value is 0.431 , meaning that if there is a perceived increase of ease of use of 1 unit will affect student's satisfaction of 0.431 unit. This research result indicates the similar result with previous research conducted by Almarashdeh (2016) and Amin, Rezaei, \& Abolghasemi (2014) which states that mobile learning should be easy to use and easy to learn, overall mobile learning should be considered easy to use. Likewise in this study, LMS can be used anywhere and anytime without any geographical restrictions. LMS is expected to be flexible for both website and mobile application. 
Communication quality proved not to significantly affect user satisfaction because the value of p-value perceived usefulness is 0.570 , which is greater than 0.05 . This indicates that communication quality factor does not affect student's satisfaction to learning management system (LMS). This research result is not similar with previous research by Wang and Chiu (2011) which stated that communication quality is significant to user satisfaction, where the results of the research stated that sharing information, giving information feedback, and exchanging opinions among users on the disccusion board can help e-learning users interact with each other, and therefore can improve student satisfaction with e-learning system learning.

Six hypotheses have been tested, there are three variables that significantly influence the satisfaction of the students (user satisfaction) using learning management system (LMS) that is information quality, service quality, and perceived ease of use.

\section{Conclusion}

From the result of this research, it can be concluded that student satisfaction towards learning management system influenced by information quality which have influence to user satisfaction equal to 0,173 , service quality which have influence to user satisfaction equal to 0,431 , and perceived ease of use which have influence to user satisfaction equal to 0,218 . Variable service quality has the highest coefficient value of other variables. This overall result shows that service quality is the most dominant factor affecting students' satisfaction on learning management system (LMS).

\section{References}

[1] S. J. Daniel, "Making Sense of Flexibility as a Defining Element of Online Learning," World Conference on Online Learning Teaching in the Digital Age, 2017.

[2] V. Stantchev, R. Colomo-Palacios, P. Soto-Acosta and S. Sanjay, "Learning management systems and cloud file hosting services: A study on students' acceptance," Computers in Human Behavior, pp. Volume 31, 612-619, 2014.

[3] N. A. Adzharuddin and. L. H. Ling, "Learning Management System (LMS) among University Students: Does It Work?" International Journal of e-Education, e-Business, eManagement and e-Learning, pp. Vol. 3, No. 3, 2013.

[4] E. Sriwardiningsih, "Faktor - faktor yang mempengaruhi perilaku belajar mahasiswa elearning," BINUS BUSINESS REVIEW Vol. 5 No. 2, pp. 564-570, 2014. https://doi.org/10.21512/bbr.v5i2.1027

[5] H. C. Wang and Y. F. Chiu, "Assessing e-learning 2.0 system success," Computers and Education 57, pp. 1790-1800, 2011. https://doi.org/10.1016/j.compedu.2011.03.009

[6] I. Almarashdeh, "Sharing instructors experience of learning management system: A technology perspective of user satisfaction in distance learning course," Computers in Human Behavior, pp. Vol 63, 249-255, 2016.

[7] E. Turban, E. McLean and J. Wetherbe, Information Technology for Management, United States of America: Wiley, 2004. 
[8] H. Miller, "The Multiple Dimensions of Information Quality," Information System Management, Vol 13, Issue 2, 1996.

[9] J. B. Walther, "Interpersonal Effects in Computer-Mediated Interaction: A Relational Perspective," Communication Research, 1992. https://doi.org/10.1177/009365092019001003

\section{$7 \quad$ Authors}

Jenny Ohliati was graduated from Binus University and now pursuing her master's degree in management information system in Binus University. She has interest in management information system and e-business.

Bahtiar S. Abbas is a Professor of Operation Research and currently also the Director and Intellectual Capital at the Bina Nusantara University (bahtiars@binus.edu)

Article submitted 28 August 2018. Resubmitted 18 October 2018. Final acceptance 20 October 2018. Final version published as submitted by the authors. 